\title{
ORGANIZATIONAL STRUCTURE FOR DISASTER MANAGEMENT PROJECTS
}

\author{
ABDON DE PAULA ${ }^{1}$, ADRIANA LEIRAS $^{1} \&$ ALESSANDRO LUKOSEVICIUS $^{2}$ \\ ${ }^{1}$ DEI - Pontífice Universidade Católica do Rio de Janeiro, Brazil \\ ${ }^{2}$ Universidade Federal Fluminense, Brazil
}

\begin{abstract}
This paper aims to contribute to a solution of the disaster coordination problem through designing an organizational structure of project for the humanitarian activities based on the PRINCE2 method and military organizational combat frame. This frame incorporates the robustness of military perspective while considering the appropriateness of maintaining the administration under civilian direction. The PRINCE2 method has been used worldwide, and the military organizational combat frame has been tested under harsh conditions. The designed structure for a humanitarian project (HP) provides a clear role and responsibility for each element of the organization, facilitating the application of leadership and minimizing uncoordinated activities performance. This structure allows the adequate flow of information from the processes of the disaster scene. The paper approach is an exploratory qualitative bibliographic applied research.
\end{abstract}

Keywords: disaster, project structure, PRINCE2, military force structure.

\section{INTRODUCTION}

Coordination is the key point of disaster response operations. Establishing coordination efforts in disasters are challenging because of the presence of many organizations providing humanitarian aid (as non-governmental organizations, bodies of United Nations, Military Forces) according to Jensen [1]. When the mentioned agencies combine their efforts to provide solutions, the lack of coordination problem appears as presented by Pilbeam [2]. So, there is the need for an overall organizational structure that can grant the necessary performance integrating several independent agencies for guaranteeing the adequate combined actions in the recovery phase and response phase.

This paper aims to contribute to a solution of the disaster coordination problem through a project organizational structure stablished over the several acting agencies in the scene. In this frame design, we use the PRINCE2 method as created by Office of Government Commerce (OGC) [3] to guarantee the necessary accommodation. Adding the military experience in the frame, we try to provide a robust adaptability to the structure when dealing with highly dynamic environments, but maintaining the administration under the civilian approach.

Our approach to the humanitarian projects (HP) is bibliographic and exploratory. In the absence of empirical data, we select to include a PRINCE2 certified practitioner point of view. We also articulate the resulting idea with a military staff structures and operational concepts, as stated by Weeks [4]. The selected PRINCE2 method allows a framework suiting to the scenario conditions, adding effectiveness in dealing with the highly changeable scene.

We organize this paper into six additional sections. In Section 2, we brief the applied methodology. In Section 3, we provide a literature review of the need for coordination in disaster and the consequent need for an organizational structure. In Section 4, we explain the development basis of the designed humanitarian organizational project framework as a solution for the presented issues. In Section 5, we submit the humanitarian project structure. In Section 6, we discuss aspects related to the HP organization. Finally, in Section 7, we present the conclusions. 


\section{METHODOLOGY}

According to Gil [5], this paper presents an applied qualitative research with the objective of investigating in the literature the coordination issues as a primary concern related to the activities after an event of a disaster. Therefore, this research can be further classified as exploratory research because had the objective of providing more familiarity with the coordination problem subject and several solutions based on organizational concepts.

The research has been a bibliographic one. The first step explores the scientific literature to further understanding the coordination theory and the nature of the published related issues on disasters. The problem has been formulated and a solution has been progressively developed over the best aspect of solutions found in the reviewed literature, trying to assemble a frame that may prove to be an effective solution.

We consider the pragmatic observation of Weeks [4] with his modeling the military organization solution considering the similarities of the disaster with a battlefield.

In the literature, there are valuable partial contributions, so we decided to add a practitioner project view and a military practitioner view to consider important characteristics of the temporary joint actions. Therefore, we propose a robust conceptual organization that allows the necessary planning, fast operations, and control. We select a project structuring method, PRINCE2 by OGC [3], that can have the necessary adjustments.

Therefore, this study is established over three essential pillars to achieve the primary goal: (i) theoretical project foundation; (ii) PRINCE2 project management method; and (iii) military combat organization. We bring a closer collaboration between theory and practice by uniting applied academic research in disaster to a practitioner view of a project organization.

\section{LITERATURE REVIEW}

\subsection{The coordination issue and solutions based on military type concepts}

Coordination is the key point of disaster response operations according to Jensen [1]. Establishing coordination efforts in disasters are challenging because of the presence of many organizations providing humanitarian aid (as non-governmental organizations, bodies of United Nations, Military Forces). When the mentioned agencies combine their efforts to provide solutions, the coordination problems appear as presented by Pilbeam [2] introducing the need for an organizational structure to integrate all efforts involving organizations that are likely to be different, possessing different priorities, objectives, and interests to protect. Their line management structures may not suit the project work, but they have to perform together in a cross-functional way as defined by the OGC [3].

Seipel [6] emphasize that coordination in disaster response has always been complicated, especially regarding civil-military cooperation. Dealing with military personnel brings the need for a frame that would suffice and prove to be useful correctly positioning a responsible authority. In a due proportion, this fact is also valid when dealing with the independent organizations present at the event, because they may have a tendency to exercise independent work in an uncoordinated manner. Also, very often, during the response, no matter the will of the involved actors of working together, they are not included in the planning processes, either.

Heterogeneous individuals and temporary organizations collaborate to provide the most desired specialized work, actions, and knowledge in the response phase. It is unreasonable to expect that the coordination of the operations can take place only with the idea of "understanding of the activities". There are several secondary aims for the different organizations that may contend with the declared primary purpose. According to Pilbeam [2], 
mutual adjustment and standardization of skills may be relevant to the coordination of shortterm events in disaster projects. In addition, he expects the achievement of coordination by mutual adjustment among individuals or small groups working in complex and dynamic environments.

The United Nations Office for the Coordination of Humanitarian Affairs (UN-OCHA) [7] presents the idea that it would play a fundamental role in operational coordination in crises, but its coordination concepts do not suffice as project direction.

On the other hand, Jahre and Jensen [8] suggest cluster thinking as a solution to the lack of coordinated disaster response. Rather than explicit coordination, they present clusters to be the conceptual level of coordination. Their solution is still very much dependable of solving the conflict of interests in a very cooperative fashion. Besides, the general organization of clusters is not a project frame.

Kovács and Spens [9] present the disaster in three different phases: preparation phase (before the disaster occurrence), response phase and recovery phase. The preparation phase is not time limited. Therefore, it is not initially suitable for HP management. According to the Project Management Institute (PMI) [10], classifying as a project is valid for the humanitarian activities set in the recovery phase and response phase, where they fit perfectly as a project because temporality is not just a perceived characteristic of such humanitarian activities but is an essential goal.

In South Africa, Reid and Van Niekerk [11] argue that a consistent response requires the application of a previously accepted management model by numerous government agencies. The findings demonstrate that for the proposed model to function effectively it is necessary to refine each level of response regarding authority, communication and reporting lines. Also, the model solution is involved with very similar requirements of the combat military structures with it is suitable to manage the chaos of the scene in a disaster because it is very analogous to a battlefield.

Therefore, to provide this mentioned agility, it is natural to bring the central concepts from the military forces to the catastrophe management, for instance, applying a command and control structure in the disaster framework. The US Army [12], establishes that the duly designated commander directs the joined forces exercising authority using command and control functions for accomplishing the mission. The duties are to be performed using an arrangement of staff, processes, equipment and systems for the adequate planning, direction and control of the operational forces for the fulfillment of the mission. The remarkable contribution is the fact that such accommodation, in the right proportions, can be applied to civilian organizational structures of disaster that may integrate civilians of various organizations, volunteers, and military personnel.

Rao [13] proposed the institutionalization of the Incident Command System (ICS) with the Indian System of Disaster Management. ICS is a system inspired by a military organization solution. The rationale foresees the use of ICS for managing all types of disasters once it is an event management system. According to him, it has the necessary flexibility. Also, it is based on scientific principles of management, and it ensures an excellent utilization of resources. The ICS weaknesses include: (1) the intensive terminology; (2) the extensive amount of functionary training; and (3) he states that there is no proper role for the already existing institutions and the non-governmental organizations (NGOs) leading to conflicts.

At last, but not least, military forces are typically used in the efforts of the answer as presented by Weeks [4]. The military units offer mobility and quick response. They face the same difficulties of any civilian organization regarding those environments. However, they are used to produce reports with learned lessons, and they are used to work in a very well 
structured organization, with well-defined elements with the sufficient authority. Weeks [4] presents a solution subject to a military administration, but the importance of his contribution is in the recognition that military groups need a complete vision of the organization to map themselves into this frame. The same need for several groups that are present at the disaster scene.

\subsection{Reasons for a project framework with scenery adaptations}

The solutions of using military project organization may result in conflicts when including civilians. Civilian project with military type organization implies in a minimum permanent structure to be maintained, providing extensive and expensive training. Commercial project structure requires a lot of scene adaptation. Therefore, we visualize a solution based on the adequate project frame adapted to the scenery that would include the best characteristics of the reviewed solutions.

As stated by the OGC [3], there must exist a specific project management team structure bringing roles and responsibilities of the elements in the project and providing the means for effective group communication to get different organization working together in a finite time for a common purpose. This organizational structure defines how the activities are conducted to achieve the objective. Such a structure can be considered as the perspective from which individuals see their organizations and the environment in which they operate, according to Jones [14]. The structure may function as the skeleton that supports the entire venture body working dynamically.

Usually, it is required a project method that allows acclimation and takes into consideration the different scenarios as foreseen by PMI [10]. As a project, the disaster scenario brings to the time management a unique flavour. Recursively, the time factor intensively modifies the characteristics of all the applied solutions, including minimizing the control of cost in the response phase.

The method of the OGC [3] provides an initial well-organized frame capable of implementing the all the mentioned functions duly, and the designed adaptations increase the potential function performance. The explanation of US Army [12] justifies including a Command, Control and Information System in the HP organizational structures. Although some questions remain unsolved, the idea behind the HP structure is to minimize the problems originated when we try to provide solutions using grouped agencies. The frame of the project centralizes the authority. Therefore, it facilitates the coordination activities.

"Organizing a social action in a world where there is no overall mind" is the definition of coordination proposed by Lepori [15, p. 359]. Following this inspiring definition, this paper aims to solve the lack of coordination issue occupying exactly the place of the "overall mind" with an organizational structure. In such structure, coordination, whatever is the selected definition, is achieved by a combination of internal rule systems and hierarchical authority.

4 DEVELOPMENT OF AN HP ORGANIZATIONAL FRAMEWORK AS A SOLUTION The OGC [3] recommends a structure within levels, as shown on the left-hand side of Fig. 1. The level that we address here is the Management level because this is exactly the managerial level required to integrated the Operative level where the agencies act. The Strategic level is outside the project management structure, and it is responsible for the project organization, the identification of the Executive of the project and the tolerance that will enable an agile management. This is also the level for disaster organizations and that takes care of planning before the catastrophe happens. The Direction level of the project is responsible for driving within the rules and limitations, and it is in charge of the success of the project. The Management and Delivery levels establish the disaster front conduction of the project. 


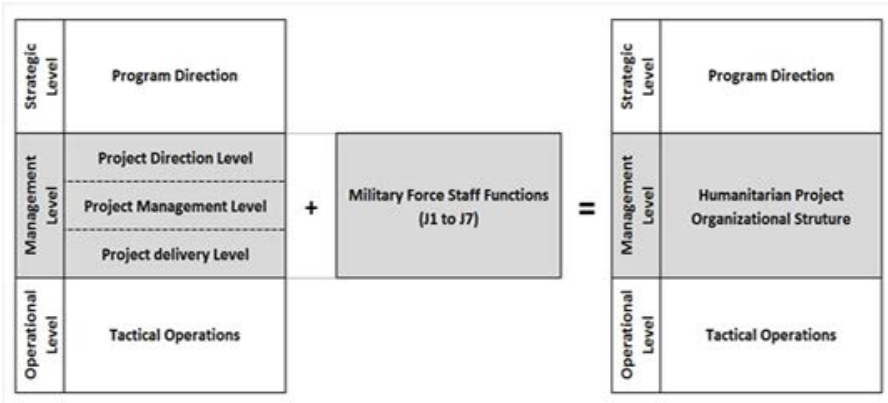

Figure 1: The basic design of humanitarian project organizational structure.

We provide a method acclimation as foreseen by the OGC [3] (the right-hand side of Fig. 1) by adapting the Management Level with the Military Staff functionality. The resulting frame incorporates a numbered military system for the general staff condensed in Table 1 similar to what was given by Weeks [4].

The idea is to have a robust organizational structure that makes possible to deal with uncertainties of the disaster environment as Weeks [4] emphasizes. Because such structures are temporary, he brings the need for providing a common cognitive map to help immediately making sense to everybody involved. This point also justifies the conformation using the military battlefield staff functions into the structure of the project organizational framework because not applying the Principles of Organization and Formalization may result in additional stress for the team and may affect negatively the performance as declared by Weeks [4]. The author also considers vital to have a central point of data collection. The conceptual project structure includes those ideas. Also, any military organization rapidly understand the project line of command, and any civilian volunteer organization can be incorporated with a minimum of orientation.

The concept aggregates the military structure clear map as declared by Weeks [4] to the following OGC [3] method characteristics:

- It provides common language;

- It brings a distinct definition mechanism of project objectives;

- There is explicit recognition of project responsibilities;

- It prescribes to do only the necessary planning using the high philosophy of management by exception providing efficient and effective use of time;

- Complete organizational framework for conducting an HP;

- The structure shall include all stakeholders.

Table 1: Military staff functions assigned to the specialized manager functions.

\begin{tabular}{|l|l|}
\hline Specialized manager & Functions \\
\hline J1 - Manpower & Commonly known as human resources \\
\hline J2 - Intelligence & Collecting data and providing information on the state of the situation \\
\hline J3 - Operations & core mission \\
\hline J4 - Logistics & Timely transportation of supplies and personnel and proper storage \\
\hline J5 - Plans & Situational approach plans \\
\hline J6 - Communications & Communication and information technology systems, and media management \\
\hline J7 - Engineering & Infrastructure damage and reconstruction support \\
\hline Note: & Both J5 and J7 are incorporated in the project support \\
\hline
\end{tabular}




\section{CONTEXT OF HUMANITARIAN PROJECT}

Based on the concepts shown in Fig. 1 we have designed the project framework presented in Fig. 2. In this framework, it is possible to verify the association of specialist manager functions with the typical features of general staff of the military (J1 to J7). For instance, in the disaster field, any organization that has personnel issues is to report to $\mathrm{J} 1$ - Manpower. Also, the manager dealing with the communications is J6 that will try to reduce the possible weak links. Here lies a crucial difference to the military staff because the specialized managers are also responsible for overseeing the action at the operational level and may be used for the production of a result.

The previously structure can provide a broad view of the scenario and the ability to supply effective control of the situation with the right authority. This structure is to furnish a real joint effort of most (if not all) organizations present at the event.

As in the original PRINCE2 model, the Strategic level is not in structuring the project (as well as the operating level). This level corresponds to the government direction, and it is a permanent part and aims to maintain the repository of experiences, recurrent needs for every project and the required training. The Operational level is also out of the Management level and corresponds to the tactical operations previously established forces but the competent specialist managers shall direct the tactical operations in an integrated manner. The intermediate level is the object of design by using the method. This level will provide the necessary coordination of heterogeneous agencies.

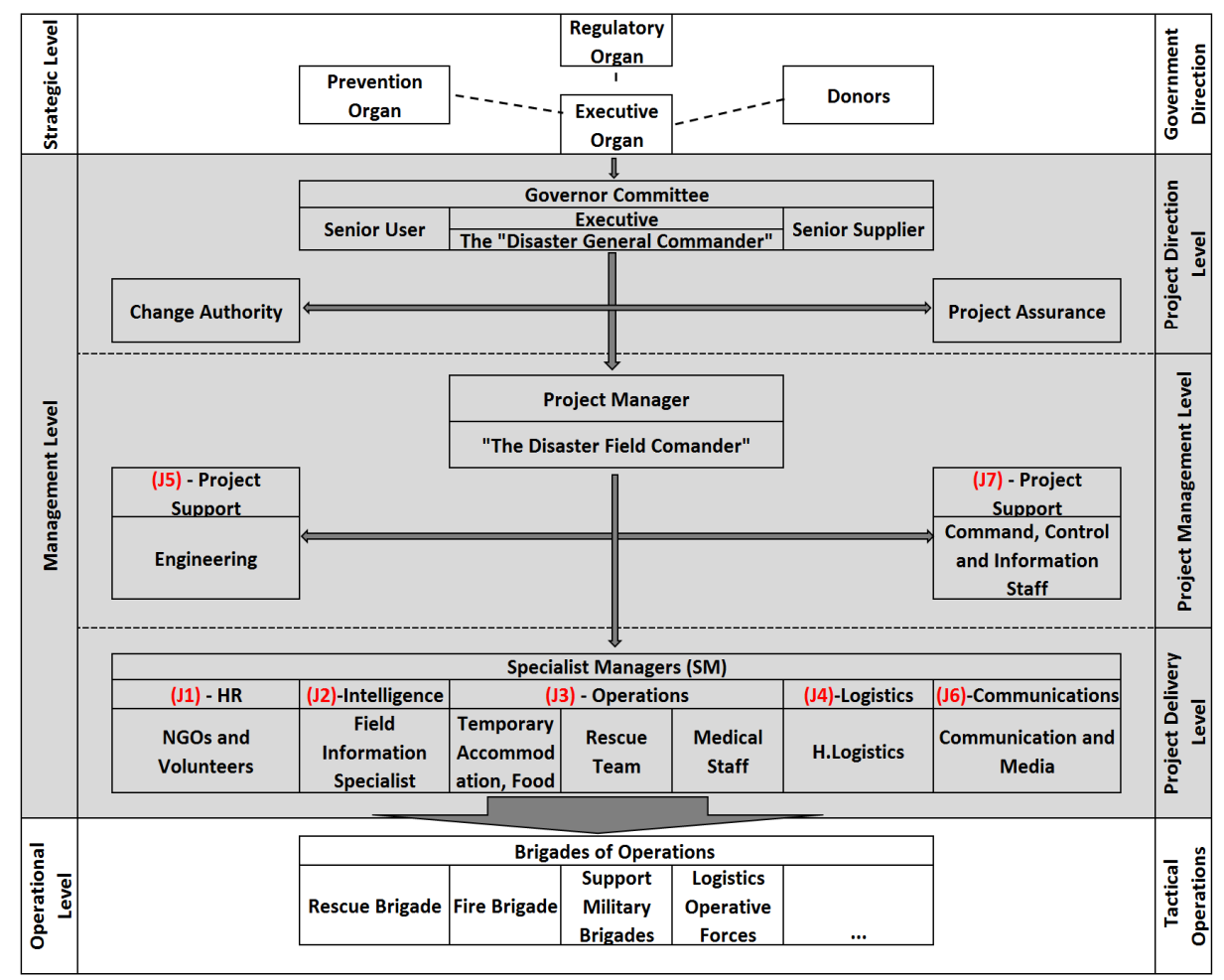

Figure 2: Organizational framework of a designed humanitarian project. 
In the structure of the HPs, consistent with the method, there are three represented interests: the government's interest, the interest of the affected population (customers) and the interests of solution providers (suppliers).

The Project Governor Committee represents all the three mentioned interests. The Executive is the general disaster commander. The committee answers for the project success. It approves plans, authorizes plan deviations, and it approves the conclusion of each project phase. The Governor Committee is responsible for communication with the affected parts. It deals with external communication management. Also, the HP has the figure of the donor that is also very close to the idea of the Company in business projects, once they provide funding for the project.

All the here represented figures are specified in the OGC [3] method. The Project Manager is the Disaster Field Commander. He lies there in the disaster front, being responsible for creating the project plan and have it approved by the Committee, responding to the daily management of the project. His team is responsible for delivering the project products and services.

There are also specialized managers to conduct the line of direction, which is the connection at the operational level. In some cases, the Staff may be separated from the functional managers to have the appropriate condition for advising the project manager in decision-making. In this organizational structure, the functional division of the specialized managers provides an almost complete need of expertise. The project team must take care of the process flows in delivering the results. Such projects take place under intense surveillance, at least on the part of stakeholders.

Crawford et al. [16] have foreseen a solution for improving project management using a participatory planning and actions, improving disaster resilience. They consider that disaster activities and operations, in the classical management approaches, consumes too much time, and they are inflexible (the HP structure corrects this error). Further, they state that disaster resilience requires a join stakeholder collaboration, once again, justifying the stakeholder presence in the framework of Fig. 2.

\section{DISCUSSION ON HUMANITARIAN PROJECT ABOUT THE ORGANIZATIONAL FRAMEWORK}

The idea behind the Weeks [4] concepts is supported by the military force organization that operates under the toughest conditions risking the highest human values. We have incorporated the basis of these notions in the project design and by providing a structure that has both military influence and civilian project concept, we try to balance the authoritarianism that would emerge from this blended structure.

We have designed just one concept of a management structure that can be used in the project for the recovery phase and the response phase. These two projects have different objectives and various time constants affecting their activities. Also, there is a radical change in stakeholders. Therefore, it is not likely to view them as just one project. The operational level will change implying that some specialized manager will change likewise, but the organizational concept will remain.

There must be a clear achievement focus to manage a recovery project as shown by Coppola [17]. Seipel [6] underscores the fragility existent in the relationship among the agents in the disaster scenario. We have to consider those feature in establishing an organizational structure for integrating the acting forces.

It shall occur the appropriate action of the staff, through the progressive planning, timely monitoring of the setting and the development of alternatives to the project leader decision-making process. For planning the actions, all the agencies must be included. 
Much of project performance is derived from the appropriate authority of the leader. The authority needs to be previously established at the right level and in the proper legal form, including the head access to the local and even national authorities. In the PRINCE2 model, authority is an essential point as declared by OGC [3].

For the project effectiveness, all the related personnel in disaster recovery have to share the same view of the longer-term development objectives when performing in the same recovery effort. As stated by Coppola [17], the ongoing efforts in Haiti case are an exceptional example of the blurred lines between relief and development that require such an understanding among response and recovery planners. Focusing is the natural characteristics of the HP, the Command, Control, and Information Systems provide a clear envision of the situation all the time.

The lessons of military forces operating on a battlefield through the concept of the Command, Control, and Information Staff System address such additional subjects. The similar functionality of the HP framework presented in Fig. 2 empowers the organization to deal with different agents including military forces and to take the opportunity to evaluate the scenario accurately, allowing the project manager to exercise the proper situational leadership.

The US Army [12] establishes that the direction by a commander of the force occurs through the application of the functionality of Command and Control that requires having an appropriated combination of personnel, equipment, communications, facilities, and procedures. Staff organizations are structured to meet the commander's critical information requirements. In the herein designed framework, a similar functional system is used as depicted in Fig. 2.

The commander and his staff focus on anticipating battlefield activities to decide and act quickly. The project manager and the corresponding staff must work in a similar manner on the disaster battlefield. For both commander and project manager, it is critical to synthesize a vast amount of data in useful information to accomplish the mission. The commander and project manager must clearly unveil their scenario visualization to their team also using the Command Control and Information Staff to guarantee the adequate execution of their idea of operations. The staff helps them communicate the vision to their teams by preparing the procedures. The team rapidly provides critical elements of the information to the commander/project manager.

With the designed conceptual structure, it is possible to implement solutions that are offered by Badiru and Racz [18]. The project manager and his staff may produce a joint plan, from gathering input, assembling a scenario view, understanding the context, defining the process and integrating the plan with others agencies, ensuring that they will be interoperable. By being located in the exact position in the scenario, they can learn from opinions, attitudes, and interest of all stakeholders.

In such structure, they can review experience and present the plans in phases. Most of all, by having a clear line of authority they can coordinate with potential partners in the response. Doing the plan together in such structure offers the opportunity of having collaborations. Besides, the structure shows the presence of a leader. It is a professional way of conducting the enterprise and not a gathering of well-intentioned amateurs.

In the framework, there is a provided space to include the media which is capable of transmitting messages about evacuation, medical assistance, and other emergency-related information. There is a specialist manager to coordinate the media information ( $\mathrm{J} 6$ shown in Fig. 1).

The weak point of the provided solution is the necessary training. However, there are already several courses in various educational institutions counterbalancing this fact. 
As a point of strength, the managers in the project structure will be working most of the time adequately apart of the disaster front in an isolated position to better analyze data and provide solutions and integrating the operational agencies.

With the balance of mentioned weakness and strengths, the following opportunities can be harnessed: the PRINCE2 is spread all over the world; there is already a body of professional and experts that may be applied in the proper model implementation. Several governments already are aware, and they implement the PRINCE2 concepts, including the United Nations. The overall development plan can integrate the governmental policy for disaster management. It would unify the global focus on disaster management.

Of course, there are threats too! A simple renaming of the function must be avoided, and the cultural aspects of the localities cannot be ignored. The PRINCE 2 ideas should be trained and practiced. Officials should be continuously formed, and the need for transfer agents has to be considered in a strategic program.

The independent organizations may involve themselves in the structure by the recognition of a well-organized structure, conducted by a competent professional, and through the project manager leading performance.

We must recall that this project must be legally established, meaning that all the authority referred to its structure shall be legitimate.

\section{CONCLUSIONS}

In this paper, we propose an organizational structure of project for the humanitarian activities based on the PRINCE2 method and military organizational structure. The objective of HP framework is minimizing uncoordinated activities performance, facilitating the application of leadership, and providing a clear role and responsibility for each element of the project.

The PRINCE2 HPs have the strengths of incorporating the standard project functions and approaches of the most modern management concepts. The use of the model ensures that the most qualified person takes charge of the disaster situation and provides the accountability for everybody. Also, the conceptual model allows much flexibility and can be adapted to different circumstances, therefore, been a robust frame. Just the practice will provide the final evaluation of the derived model. However, with the mentioned combinations of influences, we expect to aggregate the necessary qualities to overcome most of the limitations.

An appropriate structure shall allow the adequate organization and flow of information from the processes of the disaster actions, focusing energy on what is most important: saving lives.

\section{REFERENCES}

[1] Jensen, L-M., Humanitarian cluster leads: Lessons from 4PLs. Journal of Humanitarian Logistics and Supply Chain Management, 2(2), pp. 148-160, 2012.

[2] Pilbeam, C., Coordinating temporary organizations in international development through social and temporal embeddedness. International Journal of Project Management, 31(2), pp. 190-199, 2013.

[3] Office of Government Commerce (OGC), Managing Successful Projects with PRINCE2, TSO: London, 2011.

[4] Weeks, M., Organizing for disaster: Lessons from the military, Elsevier Inc. on behalf of Kelley School of Business, Indiana University, IN, 2007.

[5] Gil, A.C., Como Elaborar Projetos de Pesquisa, 5th ed., Atlas: São Paulo, 2010.

[6] Seipel, J., The impossible interface? Combining humanitarian logistics and military supply capabilities. Humanitarian Logistics: Meeting the Challenge of Preparing for 
and Responding to Disasters, eds M.G. Christopher \& P.H. Tatham, Kogan Page Publishers: London, 2011.

[7] United Nations Office for the Coordination of Humanitarian Affairs (UN-OCHA), 2016. USA Online. http://www.unocha.org. Accessed on 11 Jan. 2016.

[8] Jahre, M. \& Jensen, L-M., Coordination of humanitarian logistics through clusters. International Journal of Physical Distribution \& Logistics Management, 40(8/9), pp. 657-674, 2010.

[9] Kovács, G. \& Spens, K.M., Humanitarian logistics in disaster relief operations. International Journal of Physical Distribution \& Logistics Management, 37(2), pp. 99-114, 2007.

[10] Project Management Institute (PMI), PMBOK - Guide to the Project Management Body of Knowledge, 5th ed., Project Management Institute, Inc.: Newtown Square, PA, 2013.

[11] Reid, P. \& Van Niekerk, D., A model for a multi-agency response management system (MARMS) for South Africa. Disaster Prevention, and Management: An International Journal, 17(2), pp. 244-255, 2008.

[12] US Army, Field Manual FM101-5 Army Staff Organization and Operations. Department of the Army, Washington, DC, 1997.

[13] Rao, M.B., Institutionalization of the ICS with the Indian System of Disaster Management. Presentation on Centre for Disaster Preparedness, 2013. India, Online. http://nidm.gov.in/Presentations/ICS/Pres7. Accessed on: 11 Jan. 2016.

[14] Jones, G.R., Organizational Theory, Design, and Change, 7th ed., Pearson Prentice Hall: Toronto, 2013.

[15] Lepori, B., Coordination modes in public funding systems. Research Policy, 40(3), pp. 355-367, 2011.

[16] Crawford, L., Langston, C. \& Bajracharya, B., Participatory project management for improved disaster resilience. International Journal of Disaster Resilience in the Built Environment, 4(3), pp. 317-333, 2013.

[17] Coppola, D.P., Introduction to International Disaster Management, 2nd ed., Elsevier Inc.: London, 2010.

[18] Badiru, A. \& Racz, L., Handbook of Emergency Response: Human Factors and Systems Engineering Approach, CRC Press: New York, 2014. 